\title{
Article \\ Microstructural Characterization of TiC-Reinforced Metal Matrix Composites Fabricated by Laser Cladding Using FeCrCoNiAlTiC High Entropy Alloy Powder
}

\author{
Sangwoo Nam ${ }^{1,2}\left(0\right.$, Hyung Won Lee ${ }^{2}\left(\mathbb{D}\right.$, In-Ho Jung ${ }^{1}\left(\mathbb{D}\right.$ and Young-Min Kim ${ }^{2, *(1)}$ \\ 1 Department of Materials Science and Engineering, Seoul National University, Seoul 08826, Korea; \\ chak1843@snu.ac.kr (S.N.); in-ho.jung@snu.ac.kr (I.-H.J.) \\ 2 Advanced Joining \& Additive Manufacturing R\&D Department, Korea Institute of Industrial Technology, \\ Incheon 21999, Korea; eidos95@kitech.re.kr \\ * Correspondence: ymkim77@kitech.re.kr
}

Citation: Nam, S.; Lee, H.W.; Jung, I.-H.; Kim, Y.-M. Microstructural Characterization of TiC-Reinforced Metal Matrix Composites Fabricated by Laser Cladding Using FeCrCoNiAlTiC High Entropy Alloy Powder. Appl. Sci. 2021, 11, 6580. https://doi.org/ 10.3390/app11146580

Academic Editor: Ana M. Camacho

Received: 16 June 2021

Accepted: 13 July 2021

Published: 17 July 2021

Publisher's Note: MDPI stays neutral with regard to jurisdictional claims in published maps and institutional affiliations.

Copyright: (c) 2021 by the authors. Licensee MDPI, Basel, Switzerland. This article is an open access article distributed under the terms and conditions of the Creative Commons Attribution (CC BY) license (https:// creativecommons.org/licenses/by/ $4.0 /)$.

\begin{abstract}
TiC-reinforced metal matrix composites were fabricated by laser cladding and FeCrCoNiAlTiC high entropy alloy powder. The heat of the laser formed a TiC phase, which was consistent with the thermodynamic calculation, and produced a coating layer without interfacial defects. TiC reinforcing particles exhibited various morphologies, such as spherical, blocky, and dendritic particles, depending on the heat input and coating depth. A dendritic morphology is observed in the lower part of the coating layer near the AISI 304 substrate, where heat is rapidly transferred. Low heat input leads to an inhomogeneous microstructure and coating depth due to the poor fluidity of molten pool. On the other hand, high heat input dissolved reinforcing particles by dilution with the substrate. The coating layer under the effective heat input of $50 \mathrm{~J} / \mathrm{mm}^{2}$ had relatively homogeneous blocky particles of several micrometers in size. The micro-hardness value of the coating layer is over $900 \mathrm{HV}$, and the nano-hardness of the reinforcing particles and the matrix were $17 \mathrm{GPa}$ and $10 \mathrm{GPa}$, respectively.
\end{abstract}

Keywords: laser cladding; high entropy alloys; metal matrix composites (MMC); titanium carbide; hardness

\section{Introduction}

High entropy alloys (HEAs), which are solid solution alloys with five or more elements, maintain a relatively simple phase due to high configurational entropy [1,2]. In particular, the outstanding mechanical and high thermal properties of HEAs are expected to be applied to various structural materials such as tools, dies, molds, and furnace materials. Bulk materials manufactured by commercial casting or sintering have a size limitation [3]. On the other hand, when HEAs are used as a coating material, less amount of HEAs could be used cost-effectively and provides functionality to the surface [4]. AISI 304 stainless steel has a wide range of applications as a structural material due to its good formability and weldability, high corrosion resistance, oxidation resistance, and good toughness. However, the material requires a hard facing to overcome the disadvantages of lack of hardness and poor wear resistance. When Ti is added to the face-centered-cubic (FCC) HEAs, bodycentered-cubic (BCC) HEAs, which have higher hardness and wear performance due to the cocktail effect, are formed [5]. In addition, $\mathrm{TiC}$ is one of the most used reinforcing materials due to its high mechanical properties, chemical stability, and good wettability with $\mathrm{Co}, \mathrm{Ni}$, and Fe-based alloys [6]. Therefore, the use of $\mathrm{Ti}$ is expected to form TiC phase and strengthen the matrix, resulting in an excellent metal matrix composite (MMC) coating layer.

MMC coatings are prepared using various processes, such as gas tungsten arc cladding (GTAC) [7,8], plasma transferred arc [9], thermal spray [10], etc. In particular, the coatings 
fabricated using laser cladding have the advantages of a fast cooling rate, narrow heataffected zone, and strong interfacial bonding. The MMC manufacturing method is divided into two types, depending on whether reinforcing particles are added: the ex situ process for directly supplying the premixed reinforcing particles with metal powder and the in situ process in which the reinforcing particles are formed during the process by the reaction [11]. In the in situ synthesis method, the size of the reinforcing particles could be as small as a few microns or less, and various morphologies could be controlled by the process conditions.

There have been several attempts to develop and control the microstructure of TiC reinforcing particles in the coating layer using cladding. A study by Emamian et al. [12] found that the most crucial factor controlling the microstructure of a TiC-containing cladding layer was the dilution rate. A high dilution rate resulted in the development of dendritic structures, resulting in a rich melt pool from a high Fe content, showing lower liquidus temperature on phase equilibrium. In the study by Saroj et al. [13], when the added $\mathrm{TiC}$ fraction was low, TiC dissolved by dilution with the metal matrix. The remaining particles showed that a dendritic structure developed under at a fast cooling rate. As the $\mathrm{TiC}$ fraction increased, the spherical morphology was developed, and characteristics were inhomogeneous due to randomly aggregated spherical particles [14]. In Hamedi's work [15], pulsed lasers were employed to suppress dendritic microstructures that degrade mechanical properties. Particle morphologies were controlled under specific pulse conditions with a uniform distribution of carbon through the Marangoni convection flow. However, even under the same conditions, the temperature gradient and solidification rate vary with the depth of the melt pool, and the particle morphology was also different $[16,17]$. In the study by Cai [18], a MMC coating with FeMnCrNiCo high-entropy metal and $\mathrm{TiC}$ reinforcing particles using the ex situ method was fabricated using laser cladding. Gibbs free energy using thermodynamic calculations was employed to investigate the possibility of the formation of other carbides during the process. The coating layer adding $15 \mathrm{wt} \%$ of TiC had a hardness value of $288 \mathrm{HV}$. Liu [19] used laser cladding to form an in situ TiC reinforced $\mathrm{AlCoCrFeNi-based} \mathrm{high-entropy} \mathrm{alloy,} \mathrm{and} \mathrm{thermodynamic} \mathrm{calculations} \mathrm{were}$ used to predict the oxide phase resulting from the wear test. Ti contributed to the dispersion strengthening, solid solution strengthening, and fine-grain strengthening, resulting in a coating layer that reached a hardness of $860 \mathrm{HV}$.

Although research is being done on the manufacturing of MMCs using HEA powder and laser cladding, hardness and wear need to be further improved for commercial use. Due to its outstanding mechanical properties, the effect of laser heat input on the size, morphology, and distribution of in situ formed reinforcing particles should be analyzed. Additionally, it is also important to predict the newly formed phases during the process in a multi-component metal matrix. In this paper, a MMC coating layer with in situ formed $\mathrm{TiC}$ was fabricated by laser cladding using $\mathrm{FeCrCoNiAlTiC} \mathrm{high} \mathrm{entropy} \mathrm{alloy} \mathrm{powder}$ and an AISI 304 substrate. Gibbs free energy was used in thermodynamic calculations to predict the formation of carbide phases. In particular, the effect of the laser heat input on the morphology, size, and dispersion of $\mathrm{TiC}$ was investigated. The behavior of solidification and molten pool in the laser process was predicted by focusing on the characteristic change of the reinforcing particle according to the depth of the coating layer. In addition, the correlation between the microstructure and mechanical properties was analyzed through the micro-Vickers hardness and nano-indentation tests. Measurements, evaluations, and discussions in the paper make a critical contribution to future work on the application of laser processing of high entropy alloy powders for coating materials.

\section{Materials and Methods}

The powder alloying was manufactured by mechanical alloying using a planetary mill (Fritsch, Pulverisette 7, Germany), and the powder alloying process conditions were the same as in previous studies [7]. The amount of elemental powder used for alloying was calculated according to the molar ratio for producing $\mathrm{FeCrCoNiAlTi}{ }_{1.5} \mathrm{C}_{1.5}$. Figure $1 \mathrm{a}$ shows the experimental setup for the cladding process. The paste was prepared by adding 
distilled water and polyvinyl alcohol and then dried in an oven by blading on AISI 304 stainless steel with a thickness of $1.5 \mathrm{~mm}$, as shown in Figure 1b. The composition of the substrate and powder was analyzed with an inductively coupled plasma optical emission spectrometer (ICP-OES), and is represented in Table 1. The cladding process was carried out using a 6-axis robot (Kuka, KR 100-3, Germany) and a multi-mode disk high power laser (Trumpf, HLD4002, Germany). A Yb:YAG solid-state laser with a wavelength of $1030 \mathrm{~nm}$ and a continuous wave was used. The laser beam was a circular beam with a diameter of $3 \mathrm{~mm}$ on the surface of the substrate. The cladding layer was manufactured in an area of $50 \mathrm{~mm} \times 60 \mathrm{~mm}$, moving at pass intervals of $2.5 \mathrm{~mm}$ (Figure 1c) and was protected by argon gas. The laser output, which is the main variable, was selected by considering the change in the microstructure in the feasibility test. The cladding speed was constant at $10 \mathrm{~mm} / \mathrm{s}$, and the laser power was used in three conditions: $1.0 \mathrm{~kW}, 1.5 \mathrm{~kW}$, and $2.0 \mathrm{~kW}$. The samples were named EEMMC1.0, EEMMC1.5, and EEMMC2.0, which used entropy-enhanced metal matrix composites (EEMMC) and the laser power value. In multi-pass cladding, all passes except both end passes had overlapping areas on both sides, and the microstructure was analyzed in the non-overlapping zone. For each condition, 8 samples were taken and analyzed with an area of $12 \mathrm{~mm} \times 8 \mathrm{~mm}$.

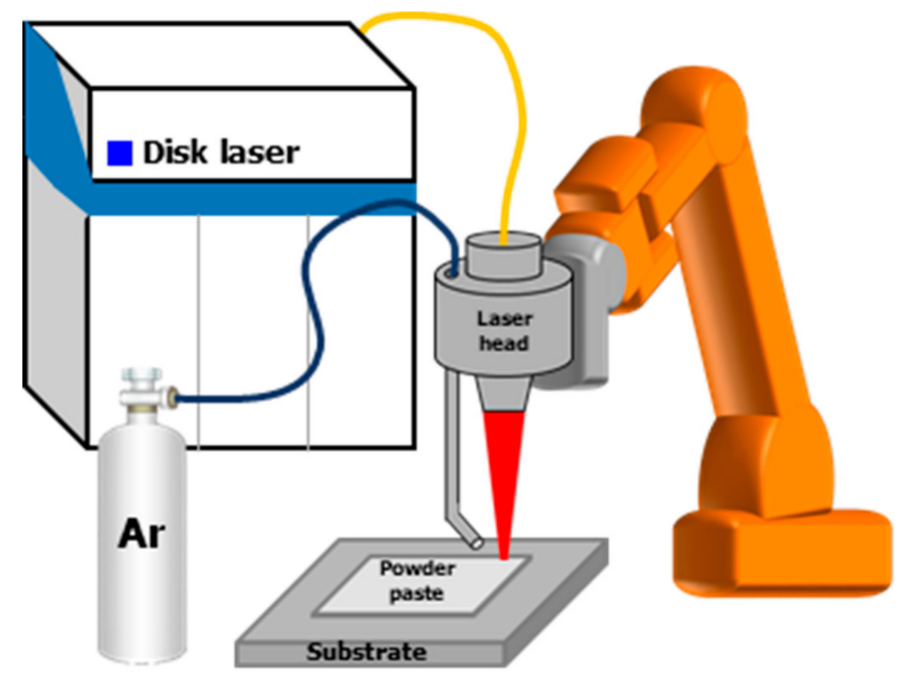

(a)

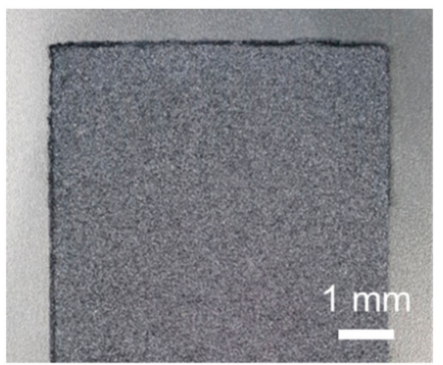

(b)

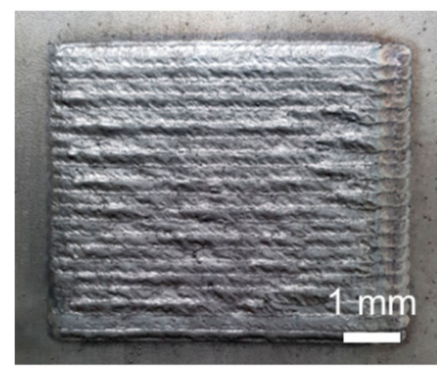

(c)

Figure 1. (a) schematic of the experimental setup. (b) HEAs powder dried on the substate before laser cladding. (c) Coating layer appearance after laser cladding.

Table 1. Chemical compositions of substrate and powder.

\begin{tabular}{cccccccc}
\hline \multirow{2}{*}{ Name } & \multicolumn{7}{c}{ Chemical Composition (wt\%) } \\
\cline { 2 - 8 } & Fe & Cr & Ni & Al & Co & Ti & C \\
\hline STS304 (substrate) & 72.2 & 18.2 & 8.0 & - & - & - & 0.06 \\
FeCrCoNiAlTi $_{1.5} C_{1.5}$ (powder) & 16.3 & 14.9 & 17.2 & 7.9 & 17.2 & 21.0 & 5.3 \\
\hline
\end{tabular}


X-ray diffraction (XRD, Rigaku, MiniFlex, Japan) was employed for phase analysis. The microstructure of the samples was observed in back-scattered electron (BSE) mode using field-emission scanning electron microscopes (FE-SEM, Thermo Fisher, Quanta 200F, Switzerland). The particle area distributions of the reinforcing particles were analyzed using image processing software (Image-Pro Plus) using 8 FE-SEM images at 5000 $\times$ magnification. Element mapping was also measured using an electron probe microanalyzer (EPMA, Cameca, SX-100, France). Micro-Vickers hardness (Mitutoyo, HM-200, Japan) was measured by indenting $0.2 \mathrm{~kg}$ for $15 \mathrm{~s}$. The hardness of the metal matrix and the reinforcing particle was analyzed separately with an ultra nano-indentation tester (Anton Paar, UNHT3, Austria). The test conditions were paused for $10 \mathrm{~s}$ at the maximum load of $20 \mathrm{mN}$, and the loading and unloading rates were performed at $120 \mathrm{mN} / \mathrm{min}$.

\section{Results and Discussion}

Thermodynamics calculations by the Factsage ${ }^{\circledR}$ software (CRCT group at Ecole Polytechnique de Montreal, Canada) developed by the CRCT group at Ecole Polytechnique de Montreal were used to design the reinforcing phase by simulating the reaction of various alloying elements with the carbon from the binder and powder. The software calculated the equilibrium phase and thermodynamics parameters for a variety of multi-component, multi-phase, and reactions. The Gibbs free energy for the formation $\left(\Delta G_{f}\right)$ in Figure 2 shows the most stable carbide among the reactions between the metal elements and one mole of carbon. When using FeCrCoNiAlTiC powder, it was necessary to confirm whether titanium carbide was a thermodynamically stable carbide in the in situ reaction. The powders were mechanically alloyed and could be assumed to be completely homogenized. Laser cladding is a non-equilibrium reaction with very fast temperature changes, which melts the powder and then solidifies rapidly. Non-equilibrium phases could also be precipitated, but the most thermodynamically stable phase is preferred. As a result of the calculation, $\mathrm{TiC}$ was found to be the most stable phase among the alloying elements in this powder, followed by chromium carbide. In Ti-free HEA alloy, the most stable chromium carbide phase except for $\mathrm{TiC}$ is formed [20]. The second stable carbide phase, chromium carbide, is formed when carbon capture Ti element enough and redundant $\mathrm{C}$ remains [21]. Both $\mathrm{TiC}$ and $\mathrm{Cr}_{23} \mathrm{C}_{6}$ are superior materials that enhance hardness and wear resistance higher than that of a stainless-steel substrate, but $\mathrm{TiC}$ had better wear resistance than chromium carbides [22]. Therefore, the spontaneous formation of titanium carbide instead of chromium carbide by adding Ti to multi-component alloy powders, such as HEAs, is important for the properties of the coating layer.

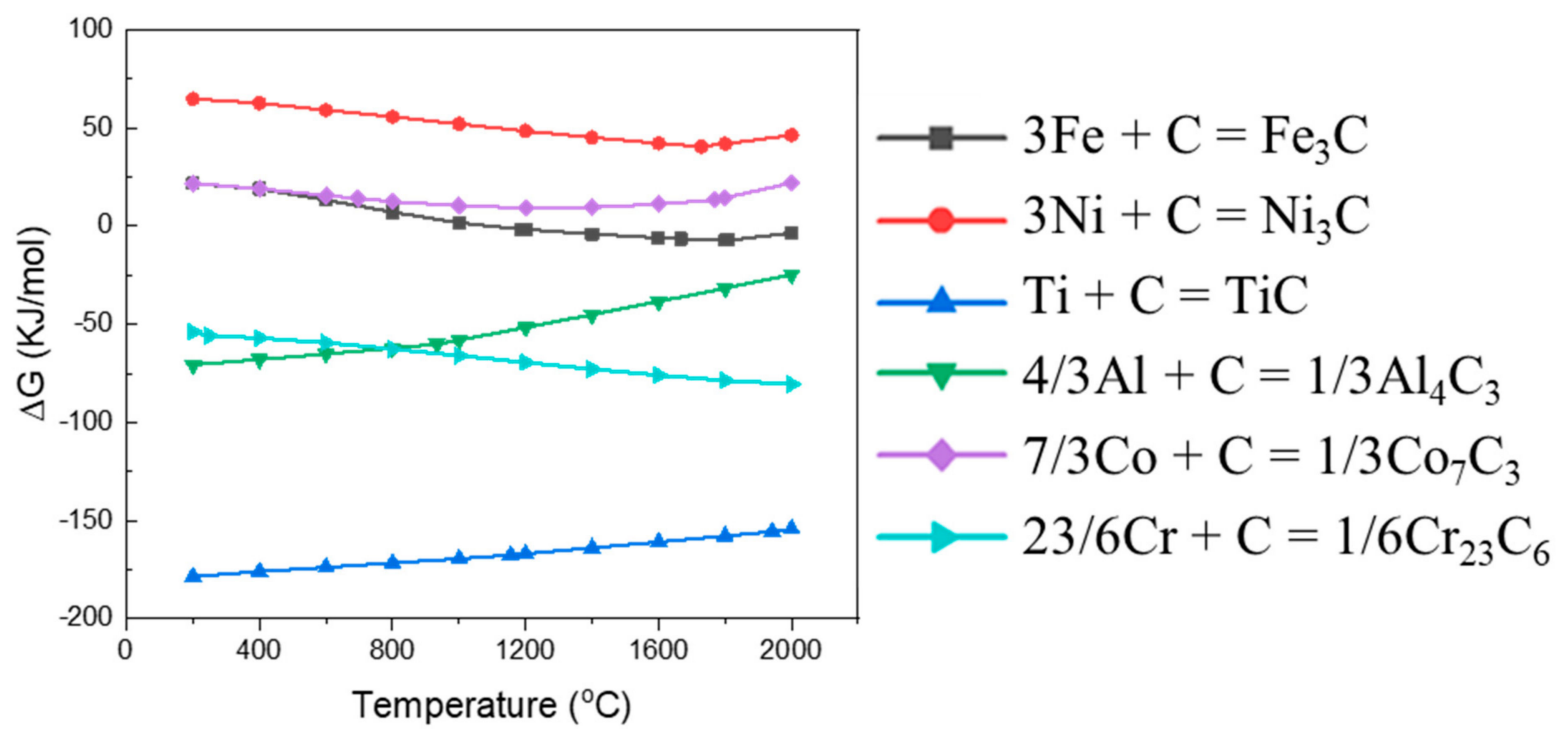

Figure 2. Gibbs free energy for formation of carbide formation reaction between 1 mole of carbon and the metal component in HEAs powder. 
TiC is formed by self-propagating high-temperature synthesis (SHS) reactions with a laser heat source [23]. The laser heat source dilutes powder and substrate to form a molten metal pool. The heat input and the flow of the molten pool affect the thickness of the coating layer and the distribution of reinforcing particles. The reinforcing particles are grown or dissolved through interaction with the liquid metal moving with the molten pool flow, and the final cladding layer is formed with the solidification by cooling. In the case of gas tungsten arc process, heat transfer occurs due to conduction and convection, and the molten pool is driven due to the various effects of the electromagnetic force, buoyancy force, arc drag force, and surface tension [24]. In the arc process, since the reinforcing particles were not mixed in the depth direction, and the flow at the surface was governed by the driving forces, it was difficult to distribute the reinforcing particles homogeneously in the depth direction $[8,25]$. The laser process had a higher energy density and faster process than the arc process, so the laser process could be a favorable environment for transporting and dispersing reinforcing particles in the depth direction.

The coating thickness in Table 2 shows the average value and standard deviation of a total of 10 values, 5 each for the peak measured at the center of the pass passed by the laser and the valley where the thinnest coating layer is formed between the passes. Effective heat input and coating thickness provide useful information about the relationship between process parameters and clad quality. Effective heat input $\left(E_{a}\right)$ was calculated by the below equation: $E_{a}=P / V D$ where $P$ is laser power, $V$ is scan speed of laser, $D$ is laser spot diameter. Since constants were used except for the laser power, the effective heat input in this study was proportional to the laser power. The coating layers of $0.6 \mathrm{~mm}, 0.9 \mathrm{~mm}$, and $1.8 \mathrm{~mm}$ were obtained in EEMMC1.0, EEMMC1.5, and EEMMC2.0, respectively, and the thickness of the coating layer increased with increasing laser heat input (Figure 3). The coating thickness with in situ synthesized TiC by GTAC is usually $0.2-0.6 \mathrm{~mm}$, and interface defects frequently occur [26]. In laser cladding with an in situ reaction, a coating layer of $0.6-1.8 \mathrm{~mm}$ thickness was prepared, which is similar to the thickness of the coating by laser cladding [12]. When comparing EEMMC1.0 and EEMMC1.5, the coating thickness increased in proportion to the laser power. However, the coating thickness of EEMMC2.0 increased significantly to $300 \%$ compared to that of EEMMC1.0. The higher the laser power, the greater coating thickness by dilution with the substrate. EEMMC1.0 were observed agglomeration of reinforcing particles as shown in Figure 3a. EEMMC1.0 is fabricated under low laser power, where it is difficult to distribute particles evenly. EEMMC1.0 has a relatively high standard deviation compared to a low coating thickness due to the irregular development of the coating layer interface and the internal microstructure. As an effective heat input increased above $50 \mathrm{~J} / \mathrm{mm}^{2}$, most agglomerated reinforcing particles seen in EEMMC1.0 were significantly reduced or disappeared.

Table 2. Cladding conditions and average thickness of the coating layer of the samples.

\begin{tabular}{cccc}
\hline Sample Name & Laser Power $(\mathbf{k W})$ & $\begin{array}{c}\text { Effective Heat } \\
\text { Input } \mathbf{E}_{\mathbf{a}}\left(\mathbf{J} / \mathbf{m m}^{\mathbf{2}}\right)\end{array}$ & Coating Thickness (mm) \\
\hline EEMMC1.0 & 1.0 & 33.3 & $0.6 \pm 0.20$ \\
EEMMC1.5 & 1.5 & 50 & $0.9 \pm 0.26$ \\
EEMMC2.0 & 2.0 & 66.7 & $1.8 \pm 0.38$ \\
\hline
\end{tabular}

Figure 4 shows the XRD results for the phase analysis of the specimens. EEMMC1.0 detected three phases of TiC, gamma phase with a FCC structure, and an alpha phase with a BCC structure. The carbide formed in the coating layer in this process was $\mathrm{TiC}$, which was consistent with the predicted stable equilibrium phase by thermodynamic calculations. The higher the laser output, the more the dilution with the substrate increased. The substrate AISI 304 stainless steel consisted of Fe-Cr-Ni as the main components and had a gamma phase. Therefore, the effect of increasing the content of $\mathrm{Fe}, \mathrm{Cr}$, and $\mathrm{Ni}$ should be investigated. In Fe-TiC alloy, secondary phases, such as $\mathrm{Fe}_{2} \mathrm{Ti}$, are generated [27]. When $\mathrm{Ni}$ is added, $\mathrm{Ti}_{2} \mathrm{Ni}$, NiTi, and $\mathrm{Ni}_{3} \mathrm{Ti}$ are developed [28,29], and $\mathrm{Cr}_{2} \mathrm{Ti}$ is detected in $\mathrm{Cr}-\mathrm{Ti}$ [30]. 
Because the metal matrix has a high configurational entropy and a fast cooling rate from the laser process, secondary phases could be suppressed. Therefore, no secondary phase picks were detected in XRD other than the main phases of gamma and alpha. The HEAs powder used in this study is a type 2, which has BCC and FCC phases, with the addition of high atomic radius elements, such as $\mathrm{Al}$ and $\mathrm{Ti}$, to a type 1 (only FCC) [31]. In EEMMC1.5, the TiC peak as a reinforcing phase exists, and alpha and gamma phases are detected as a metal matrix phase. In EEMMC2.0, the $\mathrm{TiC}$ and alpha-related peaks almost disappeared, and only the gamma-related peaks developed. This is because the dilution with the substrate increased as the heat input increased.

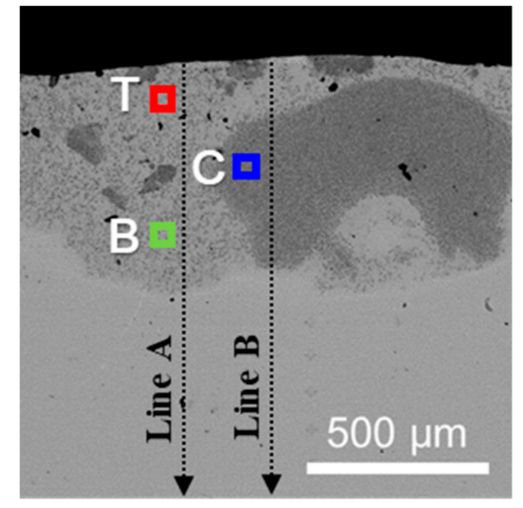

(a)

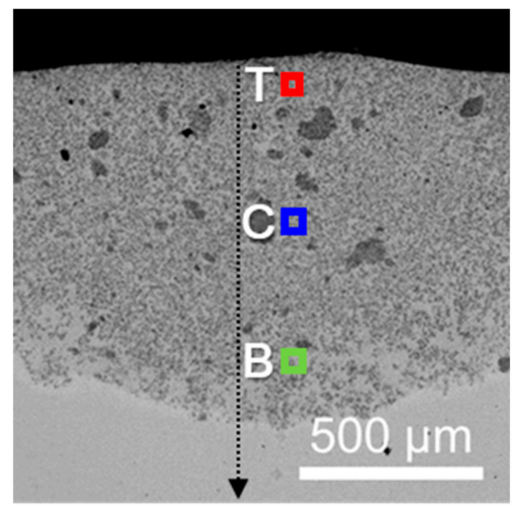

(b)

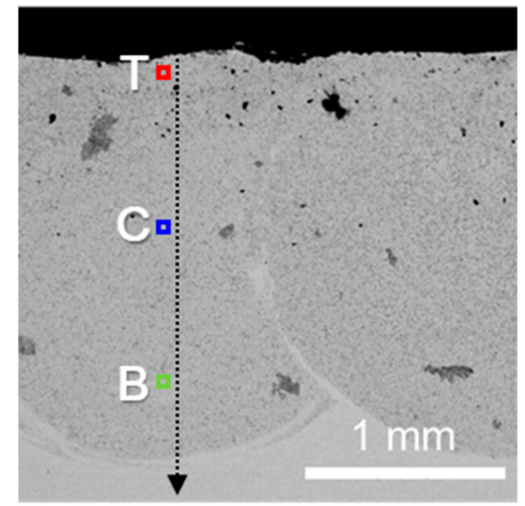

(c)

Figure 3. Cross-section image of coating layer (a) EEMMC1.0, (b) EEMMC1.5, and (c) EEMMC2.0. The squares represent the locations where the magnified microstructure images were taken, and the dotted lines are hardness measurement positions, which are employed in the following figures.

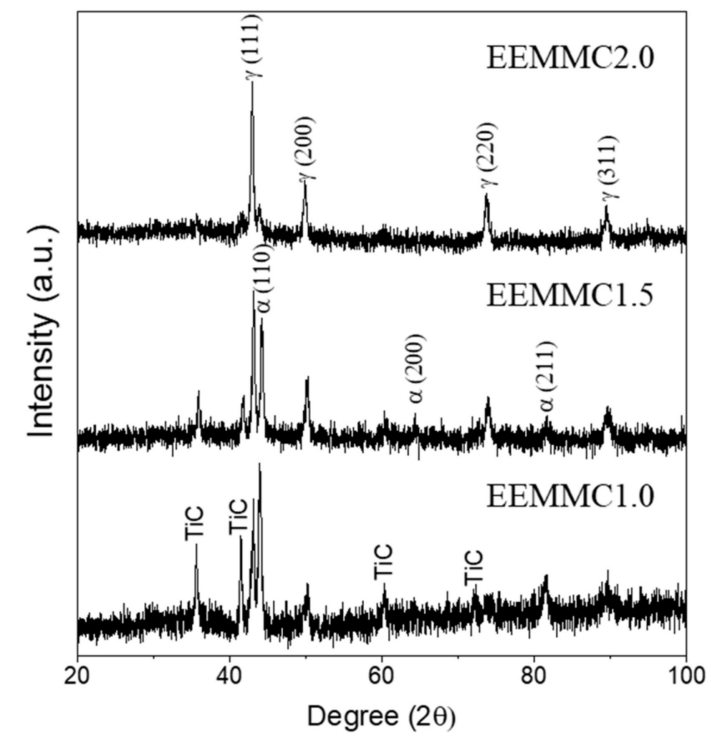

Figure 4. Phase analysis result by X-ray diffraction (XRD) results for the coating layer.

The cladding layers, EEMMC1.0, EEMMC1.5, and EEMMC2.0, were divided into three parts at $0.2-\mathrm{mm}, 0.4-\mathrm{mm}$, and $0.8-\mathrm{mm}$ intervals, respectively, considering the coating layer thickness in the depth direction. The top part $(\mathrm{T})$ close to the surface, the central part (C), and the bottom part (B) close to the substrate were divided. The sample name with the position was indicated by appending T, C, and B after the sample name. For example, the top part of EEMMC1.0 was labeled as EEMMC1.0-T. The microstructure of each section was analyzed by observing the locations marked by boxes in Figure 3 . As a result of EDS analysis, the particles with the gray darker than the metal matrix are TiC, and 
the black particles are $\mathrm{Al}_{2} \mathrm{O}_{3}$ in $\mathrm{BSE}$ mode images [7]. Figure 5 shows the microstructure typically shown in the coating layer under the conditions of Figure 3a, and Figure 5a,c are the microstructures from the top and bottom of the coating layer, respectively. As shown in Figure 5a,c, the metal matrix region had a black particle fraction of $14 \%$. The morphology of the particles showed a dendritic structure. Figure $5 \mathrm{~b}$ shows the agglomeration regions composed of sub-micron-sized $\mathrm{TiC}$ and $\mathrm{Al}_{2} \mathrm{O}_{3}$.

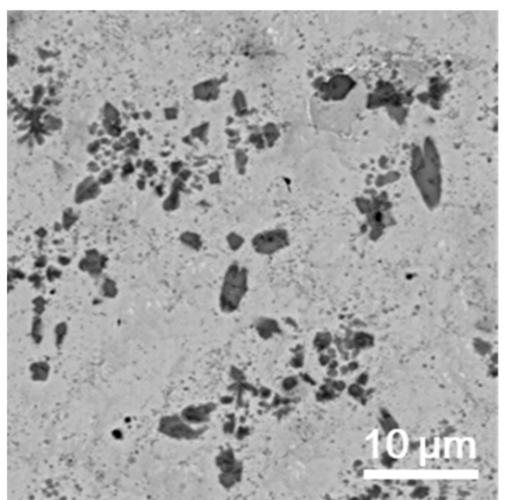

(a)

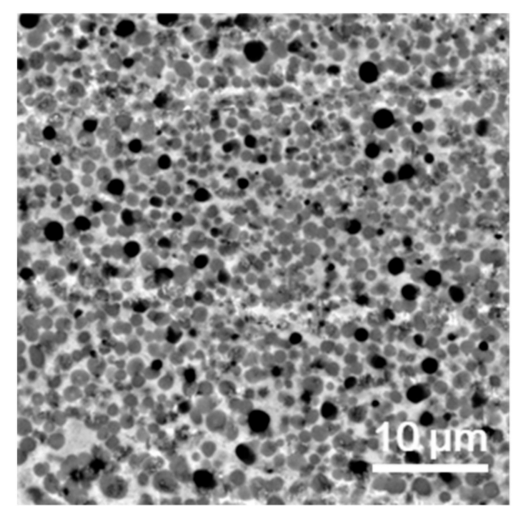

(b)

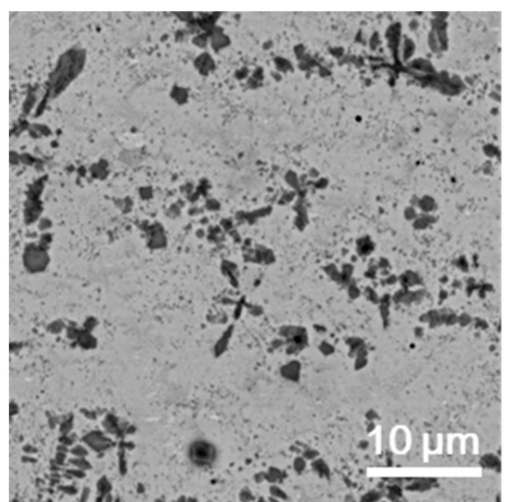

(c)

Figure 5. Microstructure at the (a) top part, (b) center part, and (c) bottom part of EEMMC1.0.

EEMMC1.5 has a thicker coating layer with more heat input than EEMMC1.0. The microstructure of EEMMC1.5 is shown in Figure 6 by dividing the coating layer into three parts in the depth direction, as shown in Figure 3, and the particle distribution was analyzed as shown in Figure 7. Most of the aggregated area of reinforcing particles seen in EEMMC1.0 disappeared, and the particles were distributed relatively uniformly. The particles formed in the EEMMC1.5 sample have a blocky morphology, indicated by yellow arrows. The blocky particles are a primary $\mathrm{TiC}$ formed at high temperature and have an isotropic polygonal shape. These particles are distinguished from secondary TiC particles with needle-like or plate-like shape located at the grain boundary [32]. Blocky particles are distinctly distributed in EEMMC1.5-T. EEMMC1.5-C had several dendritic particles with short secondary arms, and EEMMC1.5-B consisted of blocky particles and dendritic particles where secondary arms were highly developed. Dendritic particles are indicated by white arrows. The particle distribution tends to widen toward the bottom part of the coating layer due to the dendritic growth and dissolution of the particles (Figure 6). Figure 7 shows the area distribution of particles by position in the coating layer. EEMMC1.5-T had the largest number of particles with an area of 2-3 $\mu \mathrm{m}^{2}$ and had a unimodal distribution. Since EEMMC1.5-C had the largest number of particles with an area of $4-5 \mu \mathrm{m}^{2}$, the particles grew more rapidly than the top part. In addition, the particle distribution of the particles had a bimodal distribution, which increased the proportion of small particles less than $1 \mu \mathrm{m}^{2}$ and also increased particles with relatively large areas of more than $15 \mu \mathrm{m}^{2}$. EEMMC1.5-B exhibited the highest fraction of small particles of less than $1 \mu \mathrm{m}^{2}$, and particles as large as $40 \mu \mathrm{m}^{2}$ were also found. The lower the cladding layer, the faster the solidification rate and the broader the particle distribution.

EEMMC1.5-T showed a relatively uniform distribution and morphology of the particles than the other parts. The Marangoni convection created an outward flow moving back and forth at the top tail [33]. This flow helped to form homogeneous reinforcing particles on the top of the cladding layer. On the other hand, as the depth went down at the cladding layer, the coating had a relatively high cooling rate and solidified rapidly. Thus, EEMMC1.5-B had larger standard variations in particle size and developed a dendritic microstructure. The microstructure of EEMMC2.0 is shown in Figure 8 by dividing the coating layer into three parts in the depth direction, as shown in Figure 3, and the particle distribution was analyzed, as shown in Figure 9. The microstructure has fine dendritic and blocky particles. As the cladding layer lowered, like EEMMC2.0-B, the fraction of the 
particles less than $1 \mu \mathrm{m}^{2}$ increased (Figure 9). EEMMC1.5-B had a larger particle deviation than the top part. On the other hand, EEMMC2.0-B had a narrower deviation. The high heat input of EEMMC2.0 dissolved the particles, and the powder at the top diluted with the substrate and formed a coating layer. Thus, as the particles descended to the bottom of the coating layer, the particle size became smaller or completely dissolved.

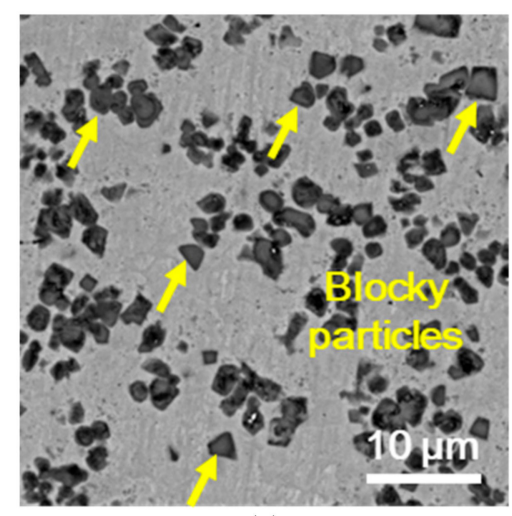

(a)

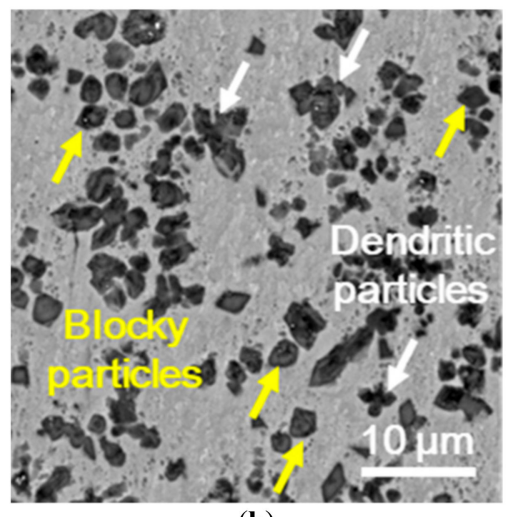

(b)

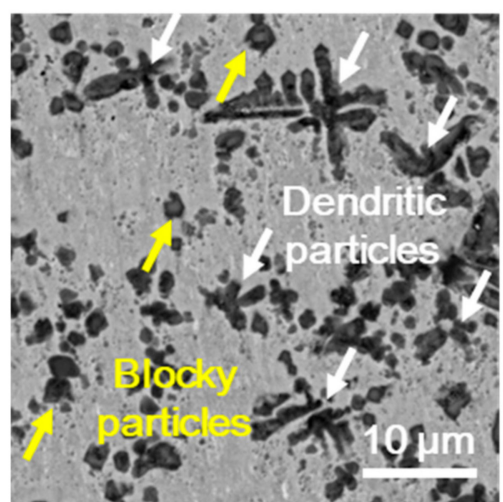

(c)

Figure 6. Microstructure of (a) EEMMC1.5-T, (b) EEMMC1.5-C, and (c) EEMMC1.5-B.

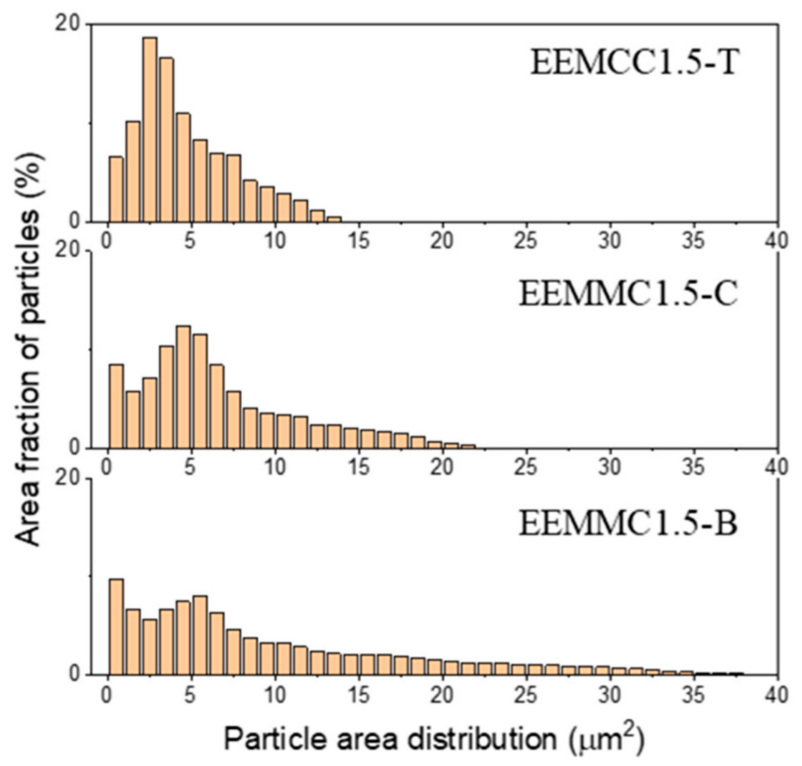

Figure 7. Area distribution of reinforcing particles in EEMMC1.5-T, EEMMC1.5-C, and EEMMC1.5-B.

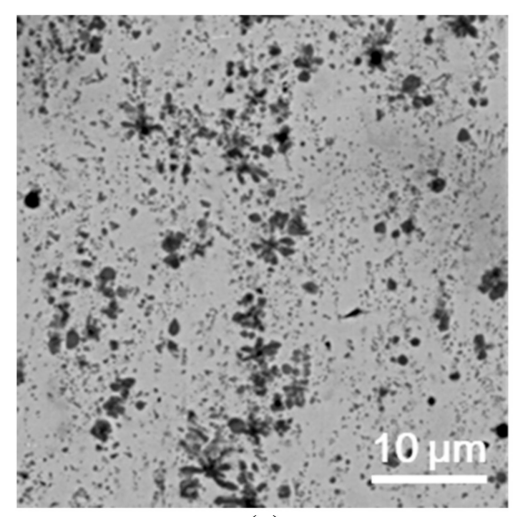

(a)

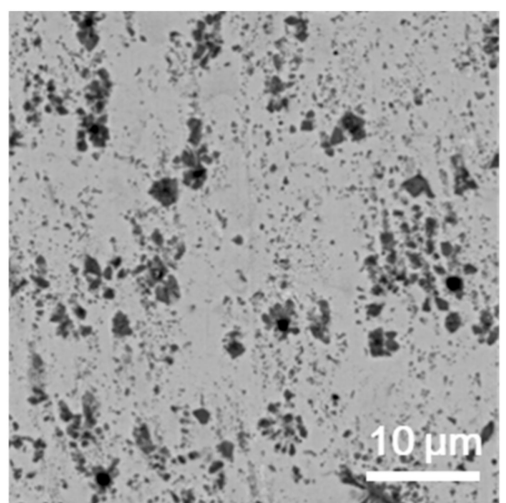

(b)

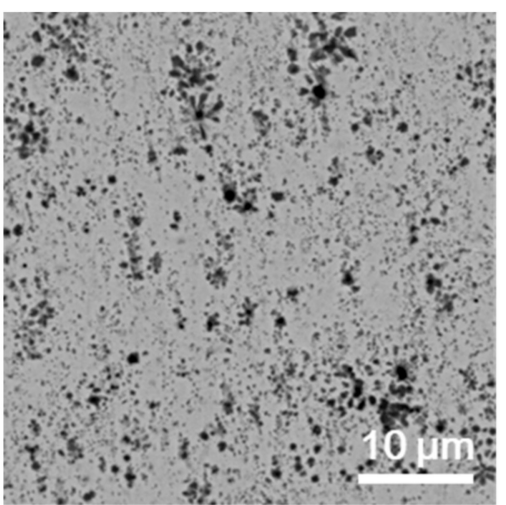

(c)

Figure 8. Microstructure of (a) EEMMC2.0-T, (b) EEMMC2.0-C, and (c) EEMMC2.0-B. 


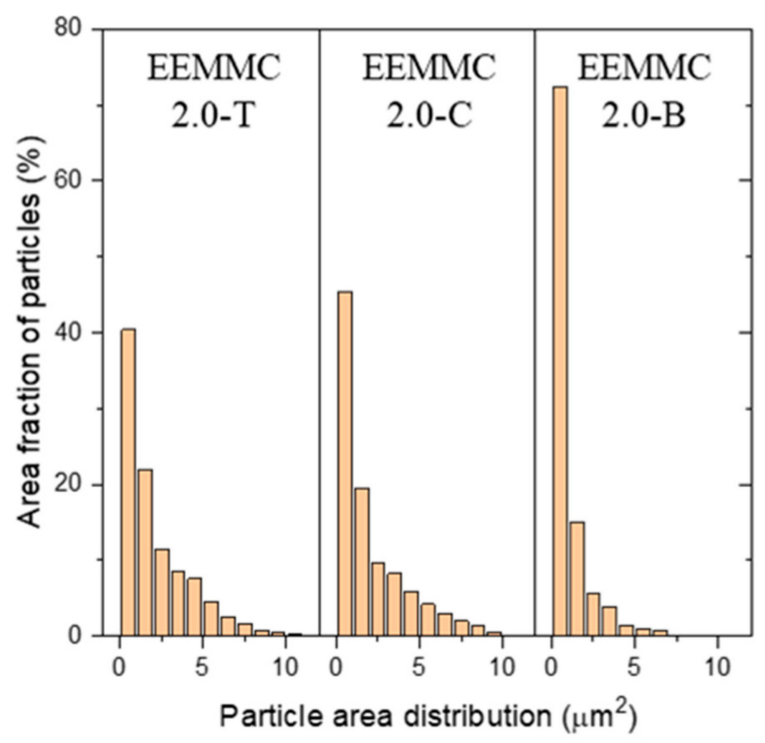

Figure 9. Area distribution of reinforcing particles in EEMMC2.0-T, EEMMC2.0-C, and EEMMC2.0-B.

EEMMC1.5-T and EEMMC2.0-T were analyzed by EPMA (Figure 10). In EEMMC1.5-T, the particles consisted of $\mathrm{Ti}, \mathrm{C}$, and $\mathrm{O}$, and the metal matrix had relatively high $\mathrm{Al}, \mathrm{Cr}$, $\mathrm{Co}, \mathrm{Fe}$, and $\mathrm{Ni}$ contents. Most of the EEMMC2.0-T showed similar distributions with EEMMC1.5-T, but the cobalt distribution was reversed, which is indicated by white arrows. In EEMMC2.0-T, there was more cobalt content in the reinforcing particles than in the matrix. The high heat input in EEMMC2.0-T dissolved the reinforcing particles and contributed to the diffusion of cobalt from the matrix to the reinforcing particles. The block-shaped particle of EEMMC1.5-T showed a distinct interface, whereas the particle of EEMMC2.0-T had a smooth interface due to diffusion. EDS analysis was measured to analyze the composition of the particles and the metal matrix by separating the particles $(\mathrm{P})$ and the matrix $(\mathrm{M})$ in the microstructure of each top part of the samples. $\mathrm{M}$ and $\mathrm{P}$ were added after the existing names, and points were used as shown in Table 3. Block-shaped particles had a very high Ti content, close to $90 \%$ in the EDS analysis (Table 3), whereas particles with dendritic morphology of EEMMC1.0-T-P and dissolved particles of EEMMC2.0-T-P had a relatively low Ti content.

Table 4 summarizes the morphology of reinforcing particles for each sample and the main mechanisms for manufacturing them. EEMMC1.0 formed a thin and inhomogeneous cladding layer due to the weak laser energy. The particles in EEMMC1.0 easily coalesce with each other, and dendritic growth occurs. EEMMC1.5-T kept the reinforcing particles homogeneously with blocky morphology and unimodal distribution. In EEMMC1.5-C and EEMMC1.5-B, small particles dissolve as the particles descended, and large particles develop dendritic growths, making the particle distribution wider than at the top part. In the case of EEMMC2.0, the reinforcing particles were diluted with the substrate material and dissolved or disappeared completely, forming a sharp distribution. The Ti content of EEMMC2.0-T-P in the reinforcing particles decreases compared to EEMMC1.5-T-P.

Table 3. EDS point analysis data (average of 5 positions).

\begin{tabular}{ccccccc}
\hline Sample & Al (at $\%)$ & Ti (at $\%)$ & Cr (at\%) & Fe (at\%) & Co (at\%) & Ni (at\%) \\
\hline EEMMC1.0-T-M & 5.3 & 4.8 & 26.2 & 50.7 & 3.3 & 9.7 \\
EEMMC1.0-T-P & 3.4 & 57.0 & 9.5 & 22.6 & 3.1 & 4.5 \\
EEMMC1.5-T-M & 13.1 & 1.4 & 24.3 & 39.3 & 7.5 & 14.3 \\
EEMMC1.5-T-P & 1.2 & 89.8 & 4.5 & 2.7 & 0.8 & 1.1 \\
EEMMC2.0-T-M & 5.8 & 2.7 & 20.0 & 57.1 & 3.1 & 11.3 \\
EEMMC2.0-T-P & 3.1 & 51.9 & 9.4 & 25.4 & 4.9 & 5.3 \\
\hline
\end{tabular}




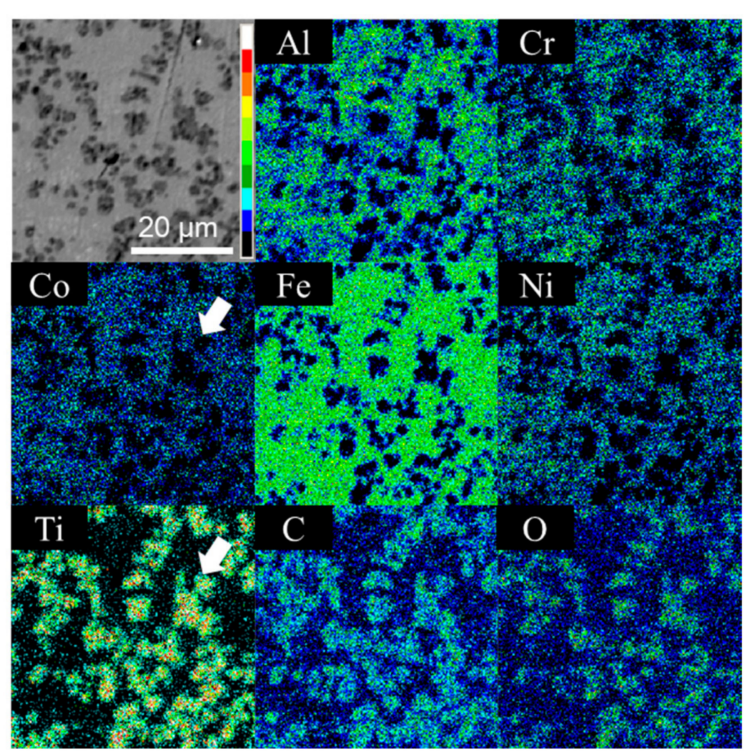

(a)

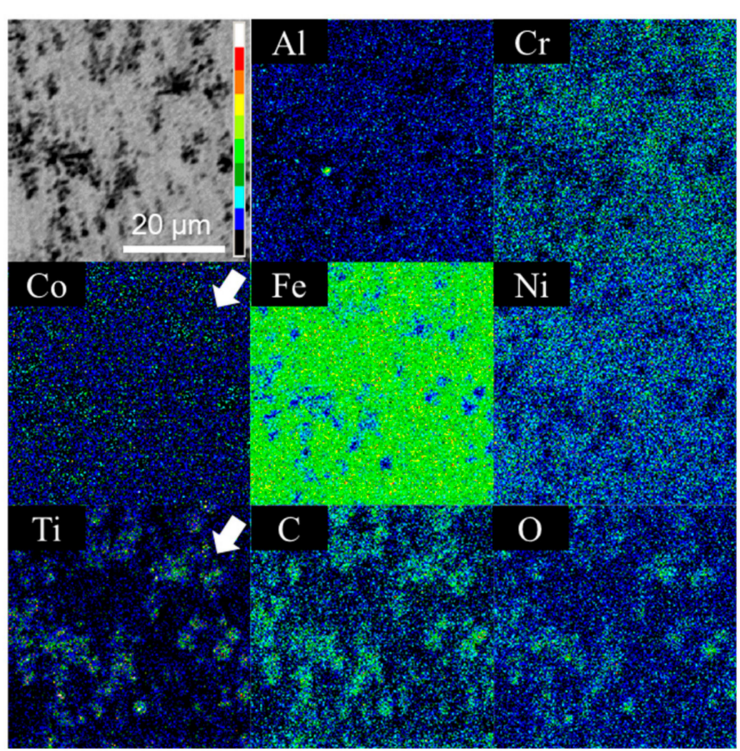

(b)

Figure 10. EPMA results for (a) EEMMC1.5-T and (b) EEMMC2.0-T.

Table 4. Morphology, fraction, and formation mechanism of reinforcing particles.

\begin{tabular}{ccccc}
\hline Sample & Particle Morphology & $\begin{array}{c}\text { Distribution } \\
\text { Characteristics }\end{array}$ & $\begin{array}{c}\text { Dominant } \\
\text { Mechanism }\end{array}$ & $\begin{array}{c}\text { Particle } \\
\text { Fraction }\end{array}$ \\
\hline EEMMC1.0-T, C, B & $\begin{array}{c}\text { Blocky and dendritic and } \\
\text { agglomerated spherical }\end{array}$ & Inhomogeneous & $\begin{array}{c}\text { Growth and } \\
\text { coalescence }\end{array}$ & 14 \& 80 ${ }^{1}$ \\
\hline EEMMC1.5-T & Blocky & Unimodal & $\begin{array}{c}\text { Equilibrium } \\
\text { Growth and } \\
\text { dissolution }\end{array}$ & 30 \\
\hline EEMMC1.5-C, B & Blocky and dendritic & Bimodal & Dissolution & 12 \\
\hline
\end{tabular}

1 The characteristics of the area where the reinforcing particles are agglomerated, as shown in Figure 5b.

The micro-hardness was measured for each sample shown in Figure 11. All samples were measured along the arrow lines in Figure 3, and EEMMC1.0 was measured at two lines due to its inhomogeneous microstructure. In EEMMC1.0, the maximum hardness of line B where spherical reinforcing particles were aggregated, was $1000-1100 \mathrm{HV}$, and the hardness of line A was found to be $400 \mathrm{HV}$. EEMMC1.5 exhibited a $0.9-\mathrm{mm}$-thick coating layer and a high hardness in the range of $700-900 \mathrm{HV}$, with values up to $900 \mathrm{HV}$ near the surface. EEMMC2.0 showed a low hardness value of 300-350 HV due to the small particle fraction and the development of a gamma phase with a FCC structure.

Table 5 summarizes the mechanical properties of the coatings measured by a nanoindentation test. The reinforcing particles of EEMMC2.0-T were too small to measure only the reinforcing particles with a nano-indenter. Since the hardness values between particles and matrix were measured similarly, EEMMC2.0-T-M and EEMMC2.0-T-P were averaged together. From the loading/unloading curves, the micro-hardness $(\mathrm{H})$ and the Young's modulus (E) were calculated, and the elastic recovery $\left(\mathrm{E}_{\mathrm{s}}\right)$ could be obtained from the area of the graph (Figure 12). $E_{S}$ can be obtained through the value of $S_{2} /\left(S_{1}+S_{2}\right), S_{1}$ is the area inside A-B-C, and $S_{2}$ is the area inside B-C-D [34]. Thus, $E_{s}$ means the ratio of elastic strain recovered during unloading to the total energy consumed in plasticity and elasticity during loading, which means resistance to plastic deformation. $\mathrm{H} / \mathrm{E}$ and $\mathrm{H}^{3} / \mathrm{E}^{2}$ are also important values that determine the wear resistance of the coating and resistance to plastic deformation, respectively $[35,36]$. Blocky particles of EEMMC1.5-T-P had higher values of factors, such as $\mathrm{H}, \mathrm{E}, \mathrm{H} / \mathrm{E}, \mathrm{H}^{3} / \mathrm{E}^{2}$, and $\mathrm{E}_{\mathrm{s}}$, than particles of EEMMC1.0-T-P and EEMMC2.0-T-P. EEMMC1.5-T exhibited a significantly higher hardness than $900 \mathrm{HV}$, even with a $30 \%$ particle fraction. Therefore, the high hardness characteristics of EEMMC1.5 
were obtained, not only from the influence of the fraction of the particles, but also by the excellent mechanical properties of the blocky-shaped reinforcing particles themselves.

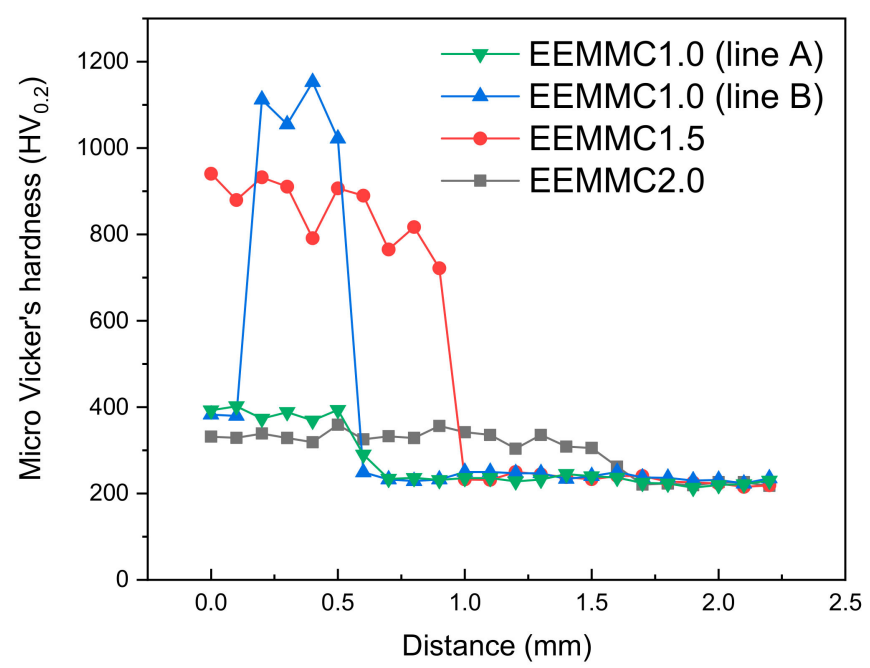

Figure 11. Micro-Vickers hardness profile measured in-depth direction from the surface of a coating layer.

Table 5. Mechanical properties of the coatings measured using nano-indentation.

\begin{tabular}{cccccc}
\hline Sample & H $(\mathbf{G P a})$ & $\mathbf{E}(\mathrm{GPa})$ & $\mathbf{H} / \mathbf{E}$ & $\mathbf{H}^{\mathbf{3}} / \mathbf{E}^{\mathbf{2}} \mathbf{( G P a )}$ & $\mathbf{E}_{\mathbf{s}} \mathbf{( \% )}$ \\
\hline EEMMC1.0-T-M & 7.61 & 170.1 & 0.045 & 0.015 & 27.6 \\
EEMMC1.0-T-P & 13.78 & 230.6 & 0.060 & 0.049 & 40.4 \\
EEMMC1.5-T-M & 9.87 & 223.6 & 0.044 & 0.019 & 31.3 \\
EEMMC1.5-T-P & 17.09 & 231.6 & 0.074 & 0.093 & 44.1 \\
EEMMC2.0-T-M,P & 6.59 & 164.3 & 0.040 & 0.011 & 23.7 \\
STS316 & 5.24 & 161.1 & 0.032 & 0.006 & 18.5 \\
\hline
\end{tabular}

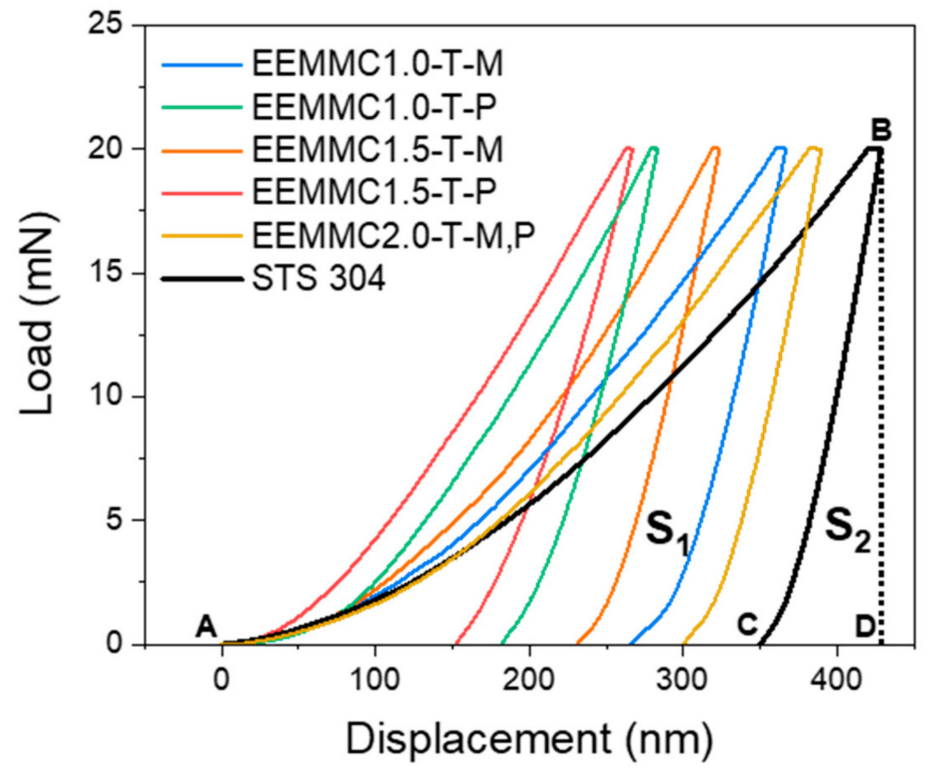

Figure 12. Load-displacement curves from nano-indentation.

\section{Conclusions}

FeCrCoNiAlTi $1.5 \mathrm{C}_{1.5}$ high entropy alloy powder was used to coat a STS304 substrate with laser cladding. The formation of a $\mathrm{TiC}$ phase using a high-temperature process and high entropy alloy powder containing carbon was predicted and verified via thermodynamic calculations and phase analysis. Therefore, the laser cladding here is an in situ 
reactive cladding, in which the formation of the cladding layer and the formation of $\mathrm{TiC}$ reinforcing particles are synthesized simultaneously. The coating layer produced in this study had a thickness of $0.9 \mathrm{~mm}$ without severe interface defects, such as pores, cracks, and delamination. Important factors that determine the size and morphology of the reinforcing particles were the heat input of the laser and the depth of the cladding layer. EEMMC1.0, which had a low effective heat input, had a non-uniform coating depth and agglomerated reinforcing particles. EEMMC2.0, fabricated with an effective heat input of $66.7 \mathrm{~J} / \mathrm{mm}^{2}$, had fine-sized reinforcing particles due to dissolution by the high energy density, increasing the coating thickness and dilution with the substrate. Under the condition where the dissolution of particles was dominant, the closer to the substrate, the smaller the particles were and the sharper the particle distribution. In EEMMC1.5, manufactured at an effective heat input of $50 \mathrm{~J} / \mathrm{mm}^{2}$, no significant agglomeration or dissolution of the reinforcing particles was observed. Compared with the top part, the lower part had a broader and bimodal particle distribution due to the dendrite growth of large particles and the dissolution of small particles. Blocky-shaped particles of several micrometers are investigated in the coating layer. The layer exhibited high micro-hardness of 700-900 HV, especially at the top over $900 \mathrm{HV}$. As the depth of the coating layer increased, dendritic morphology developed, and hardness decreased slightly. In the nano-indentation results, the particles with blocky morphology and the matrix of EEMMC1.5 were $17 \mathrm{GPa}$ and $10 \mathrm{GPa}$, respectively.

Author Contributions: Conceptualization, S.N. and Y.-M.K.; methodology, S.N.; formal analysis, S.N.; investigation, S.N. and H.W.L.; writing—original draft preparation, S.N. and H.W.L.; writingreview and editing, S.N. and Y.-M.K.; supervision, I.-H.J. and Y.-M.K.; All authors have read and agreed to the published version of the manuscript.

Funding: This research was funded by the Korea Institute of Industrial Technology as "The dynamic parameter control based smart welding system module development for the complete joint penetration weld (KITECH EH-21-0003)".

Institutional Review Board Statement: Not applicable.

Informed Consent Statement: Not applicable.

Data Availability Statement: Not applicable.

Conflicts of Interest: The authors declare no conflict of interest.

\section{References}

1. Yeh, J.W.; Chen, S.K.; Lin, S.J.; Gan, J.Y.; Chin, T.S.; Shun, T.T.; Tsau, C.H.; Chang, S.Y. Nanostructured high-entropy alloys with multiple principal elements: Novel alloy design concepts and outcomes. Adv. Eng. Mater. 2004, 6, 299-303. [CrossRef]

2. Nam, S.; Kim, C.; Kim, Y.-M. Recent studies of the laser cladding of high entropy alloys. J. Weld. Join. 2017, 35, 58-66. [CrossRef]

3. Brif, Y.; Thomas, M.; Todd, I. The use of high-entropy alloys in additive manufacturing. Scripta Materialia 2015, 99, 93-96. [CrossRef]

4. Peng, Y.B.; Zhang, W.; Li, T.C.; Zhang, M.Y.; Wang, L.; Song, Y.; Hu, S.H.; Hu, Y. Microstructures and mechanical properties of FeCoCrNi high entropy alloy/WC reinforcing particles composite coatings prepared by laser cladding and plasma cladding. Int. J. Refract. Met. Hard Mater. 2019, 84. [CrossRef]

5. Singh, S.; Wanderka, N.; Murty, B.S.; Glatzel, U.; Banhart, J. Decomposition in multi-component AlCoCrCuFeNi high-entropy alloy. Acta Mater. 2011, 59, 182-190. [CrossRef]

6. Das, K.; Bandyopadhyay, T.; Das, S. A review on the various synthesis routes of TiC reinforced ferrous based composites. J. Mater. Sci. 2002, 37, 3881-3892. [CrossRef]

7. Nam, S.; Kim, C.; Kim, Y.-M. Microstructure evolution of in-situ (Ti, W) C-Al2O3 particle-reinforced alloy fabricated by gas tungsten arc cladding. Surf. Coat. Technol. 2018, 354, 1-9. [CrossRef]

8. Sharifitabar, M.; Khaki, J.V.; Sabzevar, M.H. Microstructure and wear resistance of in-situ TiC-Al2O3 particles reinforced Fe-based coatings produced by gas tungsten arc cladding. Surf. Coat. Technol. 2016, 285, 47-56. [CrossRef]

9. Corujeira Gallo, S.; Alam, N.; O'Donnell, R. In-situ precipitation of TiC upon PTA hardfacing with grey cast iron and titanium for enhanced wear resistance. Surf. Coat. Technol. 2013, 214, 63-68. [CrossRef]

10. Tian, L.-H.; Xiong, W.; Liu, C.; Lu, S.; Fu, M. Microstructure and wear behavior of atmospheric plasma-sprayed AlCoCrFeNiTi high-entropy alloy coating. J. Mater. Eng. Perform. 2016, 25, 5513-5521. [CrossRef]

11. Candel, J.J.; Jimenez, J.A.; Franconetti, P.; Amigó, V. Effect of laser irradiation on failure mechanism of TiCp reinforced titanium composite coating produced by laser cladding. J. Mater. Process. Technol. 2014, 214, 2325-2332. [CrossRef] 
12. Emamian, A.; Corbin, S.F.; Khajepour, A. The influence of combined laser parameters on in-situ formed TiC morphology during laser cladding. Surf. Coat. Technol. 2011, 206, 124-131. [CrossRef]

13. Saroj, S.; Sahoo, C.K.; Tijo, D.; Kumar, K.; Masanta, M. Sliding abrasive wear characteristic of TIG cladded TiC reinforced Inconel825 composite coating. Int. J. Refract. Met. Hard Mater. 2017, 69, 119-130. [CrossRef]

14. Saroj, S.; Sahoo, C.K.; Masanta, M. Microstructure and mechanical performance of TiC-Inconel825 composite coating deposited on AISI 304 steel by TIG cladding process. J. Mater. Process. Technol. 2017, 249, 490-501. [CrossRef]

15. Hamedi, M.; Torkamany, M.; Sabbaghzadeh, J. Effect of pulsed laser parameters on in-situ TiC synthesis in laser surface treatment. Opt. Laser Eng. 2011, 49, 557-563. [CrossRef]

16. Lee, Y.; Nordin, M.; Babu, S.S.; Farson, D.F. Effect of fluid convection on dendrite arm spacing in laser deposition. Metall. Mater. Trans. B 2014, 45, 1520-1529. [CrossRef]

17. Chen, S.; Chen, X.; Wang, L.; Liang, J.; Liu, C. Laser cladding FeCrCoNiTiAl high entropy alloy coatings reinforced with self-generated TiC particles. J. Laser Appl. 2017, 29. [CrossRef]

18. Cai, Y.; Zhu, L.; Cui, Y.; Shan, M.; Li, H.; Xin, Y.; Han, J. Fracture and wear mechanisms of FeMnCrNiCo + x(TiC) composite high-entropy alloy cladding layers. Appl. Surf. Sci. 2021, 543. [CrossRef]

19. Liu, H.; Liu, J.; Chen, P.; Yang, H. Microstructure and high temperature wear behaviour of in-situ TiC reinforced AlCoCrFeNibased high-entropy alloy composite coatings fabricated by laser cladding. Opt. Laser Technol. 2019, 118, 140-150. [CrossRef]

20. Kunce, I.; Polanski, M.; Karczewski, K.; Plocinski, T.; Kurzydlowski, K. Microstructural characterisation of high-entropy alloy $\mathrm{AlCoCrFeNi}$ fabricated by laser engineered net shaping. J. Alloy. Compd. 2015, 648, 751-758. [CrossRef]

21. Cai, Y.C.; Cui, Y.; Zhu, L.S.; Tian, R.Y.; Geng, K.P.; Li, H.J.; Han, J. Enhancing the (FeMnCrNiCo plus TiC) cladding layer by in-situ laser remelting. Surf. Eng. 2021. [CrossRef]

22. Mourlas, A.; Pavlidou, E.; Vourlias, G.; Rodríguez, J.; Psyllaki, P. Concentrated solar energy for in-situ elaboration of wear-resistant composite layers. Part I: TiC and chromium carbide surface enrichment of common steels. Surf. Coat. Technol. 2019, $377,124882$. [CrossRef]

23. Masanta, M.; Shariff, S.; Choudhury, A.R. Microstructure and properties of $\mathrm{TiB}_{2}-\mathrm{TiC}-\mathrm{Al}_{2} \mathrm{O}_{3}$ coating prepared by laser assisted SHS and subsequent cladding with micro-/nano-TiO2 as precursor constituent. Mater. Design 2016, 90, 307-317. [CrossRef]

24. Wang, X.; Huang, J.; Huang, Y.; Fan, D.; Guo, Y. Investigation of heat transfer and fluid flow in activating TIG welding by numerical modeling. Appl. Therm. Eng. 2017, 113, 27-35. [CrossRef]

25. An, Q.; Huang, L.J.; Jiao, Y.; Bao, Y.; Zhong, B.; Geng, L. Intergrowth microstructure and superior wear resistance of (TiB + $\mathrm{TiC}) / \mathrm{Ti} 64$ hybrid coatings by gas tungsten arc cladding. Mater. Design 2019, 162, 34-44. [CrossRef]

26. Sahoo, C.K.; Masanta, M. Microstructure and mechanical properties of TiC-Ni coating on AISI304 steel produced by TIG cladding process. J. Mater. Process. Technol. 2017, 240, 126-137. [CrossRef]

27. Emamian, A.; Corbin, S.F.; Khajepour, A. Effect of laser cladding process parameters on clad quality and in-situ formed microstructure of Fe-TiC composite coatings. Surf. Coat. Technol. 2010, 205, 2007-2015. [CrossRef]

28. Yanan, L.; Ronglu, S.; Wei, N.; Tiangang, Z.; Yiwen, L. Effects of $\mathrm{CeO}_{2}$ on microstructure and properties of TiC/Ti $2 \mathrm{Ni}_{\mathrm{N}} \mathrm{reinforced}$ Ti-based laser cladding composite coatings. Opt. Laser Eng. 2019, 120, 84-94. [CrossRef]

29. Liu, Y.; Ding, J.; Qu, W.; Su, Y.; Yu, Z. Microstructure evolution of TiC particles in situ, synthesized by laser cladding. Materials 2017, 10, 281. [CrossRef]

30. Han, T.; Xiao, M.; Zhang, J.; Feng, X.; Shen, Y. Laser cladding composite coating on mild steel using Ni-Cr-Ti-B4C powder. Surf. Eng. 2018, 36, 1-7. [CrossRef]

31. Diao, H.Y.; Feng, R.; Dahmen, K.A.; Liaw, P.K. Fundamental deformation behavior in high-entropy alloys: An overview. Curr. Opin. Solid State Mater. 2017, 21, 252-266. [CrossRef]

32. Perminov, A.; Jurisch, M.; Bartzsch, G.; Biermann, H.; Weißgärber, T.; Volkova, O. Manufacturing Fe-TiC metal matrix composite by electron beam powder bed fusion from pre-alloyed gas atomized powder. Mater. Sci. Eng. A 2021, 813. [CrossRef]

33. Cho, W.-I.; Na, S.-J.; Thomy, C.; Vollertsen, F. Numerical simulation of molten pool dynamics in high power disk laser welding. J. Mater. Process. Technol. 2012, 212, 262-275. [CrossRef]

34. Cheng, J.; Liu, D.; Liang, X.; Chen, Y. Evolution of microstructure and mechanical properties of in situ synthesized TiC$\mathrm{TiB}_{2} / \mathrm{CoCrCuFeNi}$ high entropy alloy coatings. Surf. Coat. Technol. 2015, 281, 109-116. [CrossRef]

35. Leyland, A.; Matthews, A. On the significance of the H/E ratio in wear control: A nanocomposite coating approach to optimised tribological behaviour. Wear 2000, 246, 1-11. [CrossRef]

36. Musil, J.; Kunc, F.; Zeman, H.; Polakova, H. Relationships between hardness, Young's modulus and elastic recovery in hard nanocomposite coatings. Surf. Coat. Technol. 2002, 154, 304-313. [CrossRef] 